\title{
Effects of Ginkgo biloba Extract Feeding on Salt-Induced Hypertensive Dahl Rats
}

\author{
Yoko Kubota, ${ }^{a, b}$ Naoko Tanaka, ${ }^{a}$ Satomi Kagota,${ }^{a}$ Kazuki Nakamura, ${ }^{a}$ Masaru Kunitomo,,${ }^{a, b}$ \\ Keizo UmegaKI, ${ }^{c}$ and Kazumasa ShINOZUKA ${ }^{*, a}$ \\ ${ }^{a}$ Department of Pharmacology, School of Pharmaceutical Sciences, Mukogawa Women's University; ${ }^{b}$ Research Institute \\ for Biosciences, Mukogawa Women's University; Nishinomiya 663-8179, Japan: and ${ }^{c}$ National Institute of Health and \\ Nutrition; Shinjuku-ku 162-8636, Japan. Received August 22, 2005; accepted November 16, 2005
}

\begin{abstract}
We previously demonstrated that Ginkgo biloba extract (GBE) produced vasodilation via the nitric oxide synthesis and release by increasing the intracellular calcium level in vascular endothelial cells of rats. The present study aimed to clarify the effects of dietary administration of GBE on the blood pressure and vascular tone of hypertensive Dahl salt-sensitive (Dahl) rats in order to evaluate its therapeutic actions and availability. Dahl rats were fed an $8.0 \% \mathrm{NaCl}$ diet or an $8.0 \% \mathrm{NaCl}$ plus $0.5 \%$ GBE diet for $24 \mathrm{~d}$. The feeding of GBE did not change the heart rate, but significantly decreased systolic blood pressure. After 24 days' administration, the effects of GBE on the atria and aorta isolated from Dahl rats were examined. The GBE-containing diet did not affect the negative and positive actions of isolated atria that were produced by acetylcholine and isoproterenol, respectively. In the aortic preparations, the relaxation in response to acetylcholine was significantly potentiated by a GBE-containing diet. Sodium nitroprusside-induced relaxation was unchanged by GBE-containing diet. These results demonstrated that GBE reduced salt-related elevation of blood pressure and restored the impaired acetylcholine-induced vasodilation in aortic segments.
\end{abstract}

Key words Ginkgo biloba extract (GBE); Dahl salt-sensitive rat; blood pressure; aorta; relaxation

Ginkgo biloba extract (GBE), which is the leaf extract of Ginkgo biloba, has many pharmacological effects. For example, preventing ischemia-induced oxidation, ${ }^{1-3)}$ improving cerebral blood flow ${ }^{4)}$ and antagonizing the action of plateletactivating factor ${ }^{5}$ have been reported. GBE and its constituents, especially terpenoids and flavonoids, are also reported to possess vasorelaxant properties. ${ }^{6,7)}$ These findings have led us to consider the possibility that GBE might have protective effects in cardiovascular disease. However, few reports have clarified the effect of GBE on blood pressure, using an animal model of hypertension. Dahl salt-sensitive (Dahl) rats develop high blood pressure when fed salt, and are therefore similar to a subgroup of humans with hypertension. ${ }^{8,9)}$ In this study, we analyzed the effects of daily-term oral GBE treatment on blood pressure, heart and vascular function in Dahl rats.

\section{MATERIALS AND METHODS}

Animals and Materials Experiments were performed in accordance with Guiding Principles for the Care \& Use of Laboratory Animals approved by The Japanese Pharmacological Society and Mukogawa Women's University. The GBE powder was supplied by Tama Biochemical Co., Ltd. (Tokyo, Japan) and contained $24.2 \%$ flavonoids and $9.4 \%$ terpenes; similar to that of EGb $761^{\circledR 10)}$ used in European countries. Male 6-week-old Dahl salt-sensitive rats $(n=12)$ were obtained from Japan SLC, Inc. (Shizuoka, Japan). Rats were initially fed a control diet $(8 \% \mathrm{NaCl}$ addition MR stock (Japan SLC, Inc.) diet without GBE) for $7 \mathrm{~d}$. After that, the animals received $8 \% \mathrm{NaCl}$ addition $\mathrm{MR}$ stock diet (control group, $n=6$ ) or $8 \% \mathrm{NaCl}$ plus $0.5 \%$ GBE addition MR stock diet (GBE group, $n=6$ ) for $24 \mathrm{~d}$. The animals had free access to drinking water in the experiment. Rats were then anaesthetized with pentobarbital sodium $(60 \mathrm{mg} / \mathrm{kg}$, i.p.), blood was taken from the abdominal aorta, and the heart and tho- racic aorta were rapidly removed. Heart rate and blood pressure were measured by the tail-cuff method (Model MK2000, Muromachi Kikai Co., Ltd., Tokyo, Japan) in unanaesthetized rats between 13.00 and $17.00 \mathrm{~h}$, at $23-25^{\circ} \mathrm{C}$.

Materials Acetylcholine chloride, $R(-)$-isoproterenol $(+)$-bitartrate salt and noradrenalin were obtained from Daiichi Pharmaceutical Co. (Tokyo, Japan), RBI (Natick, MA, U.S.A.) and Sankyo Co. (Tokyo, Japan). Other reagents used were purchased from Nacalai Tesque, Inc. (Kyoto, Japan).

Chronotropic and Inotropic Effects on Isolated Rat Atria The isolated heart was immediately placed in a Krebs-Henseleit solution of the following composition ( $\mathrm{mM}$ ): $\mathrm{NaCl} 118.4, \mathrm{KCl} 4.7, \mathrm{MgSO}_{4} 1.2, \mathrm{CaCl}_{2} 2.5, \mathrm{NaHCO}_{3} 25.0$, $\mathrm{KH}_{2} \mathrm{PO}_{4} 1.2$ and glucose 10.0. After excess blood vessels and the ventricle were removed from the heart, the atria preparation which consists of auricular nodes and left-right atrium were mounted in a $5 \mathrm{ml}$ organ bath filled with Krebs-Henseleit solution. The chronotropic and inotropic changes were measured with a force-displacement transducer (Model T-7, NEC San-ei Instruments, Ltd., Tokyo, Japan) coupled to a PowerLab/800 (ADInstruments Pty Ltd., NSW, Australia) under a resting tension of $1.0 \mathrm{~g}$. The bath solution was maintained at $32^{\circ} \mathrm{C}$ to avoid the exhaustion condition of the atria and bubbled with a $95 \% \mathrm{O}_{2}-5 \% \mathrm{CO}_{2}$ gas mixture. Each preparation was allowed to equilibrate for at least $60 \mathrm{~min}$ prior to initiation of experimental procedures, and during this period the incubation medium was changed every $20 \mathrm{~min}$. After the equilibration period, acetylcholine or isoproterenol were cumulatively added to the bath solution.

Relaxation Studies on Isolated Rat Aorta The thoracic aorta was immediately placed in a Krebs-Henseleit solution of the following composition (mM): $\mathrm{NaCl} 118.4, \mathrm{KCl} 4.7$, $\mathrm{MgSO}_{4} 1.2, \mathrm{CaCl}_{2} 2.5, \mathrm{NaHCO}_{3} 25.0, \mathrm{KH}_{2} \mathrm{PO}_{4} 1.2$ and glucose 10.0. After removing periaortic fat and connective tissue, the aorta was cut into ring segments of approximately $3 \mathrm{~mm}$ length. Each ring preparation was mounted vertically 
under a resting tension of $1 \mathrm{~g}$ in a $5 \mathrm{ml}$ water jacketed organ bath filled with Krebs-Henseleit solution and attached to a force-displacement transducer (Model T-7, NEC San-ei Instruments, Ltd., Tokyo, Japan). The bath solution was maintained at $37^{\circ} \mathrm{C}$ and bubbled with a $95 \% \mathrm{O}_{2}-5 \% \mathrm{CO}_{2}$ gas mixture. Each preparation was allowed to equilibrate for at least $60 \mathrm{~min}$ prior to the initiation of experimental procedures, and during this period the incubation media were changed every $10 \mathrm{~min}$. After this equilibration period, the ring preparation was contracted with noradrenaline $\left(10^{-7} \mathrm{M}\right)$ before cumulatively adding putative relaxing agents. The relaxation response was expressed as a percentage of the maximal relaxation developed by papaverine $\left(10^{-4} \mathrm{M}\right)$.

Statistics All values are presented as the means \pm S.E.M. Data were evaluated for statistical significance using the Student's $t$-test. When the variances of two groups were different, the Welch test was used. A probability of less than 0.05 was considered significant. Statistical analyses were carried out with a computer program (StatView 5.0, SAS Institute Inc., Cary, NC, U.S.A.).

\section{RESULTS}

Effect of GBE Diet on Blood Pressure and Heart Rate Figure 1 shows systolic blood pressure and heart rate in Dahl rats during 24 days' administration of control or GBE-containing diets. Systolic blood pressure in control Dahl rats significantly increased with age (after days $0,8,16$ and 24 the systolic blood pressures were $129.2 \pm 5.1,142.3 \pm 2.9,158.6 \pm$ 2.3 and $166.3 \pm 3.6 \mathrm{mmHg}$, respectively). This increase was significantly suppressed by administration of GBE (after days $0,8,16$ and 24 the systolic blood pressures were $132.9 \pm 4.3,120.5 \pm 3.0,130.6 \pm 2.8$ and $145.5 \pm 3.5 \mathrm{mmHg}$, respectively). However, GBE-containing diet did not affect heart rate over the $24 \mathrm{~d}$ administration period.

Effect of GBE Diet on Isolated Rat Atria Figure 2 compares the effects of acetylcholine and isoproterenol on the atria isolated from Dahl rats receiving GBE-diet with those from Dahl rats receiving the control diet. The heart rate and contractile force in atria isolated from Dahl rats receiving GBE diet were not significantly different from those from control rats. Acetylcholine-induced negative chronotropic and inotropic actions in atria of GBE rats were not significantly different from those of control rats. Also, isopro-
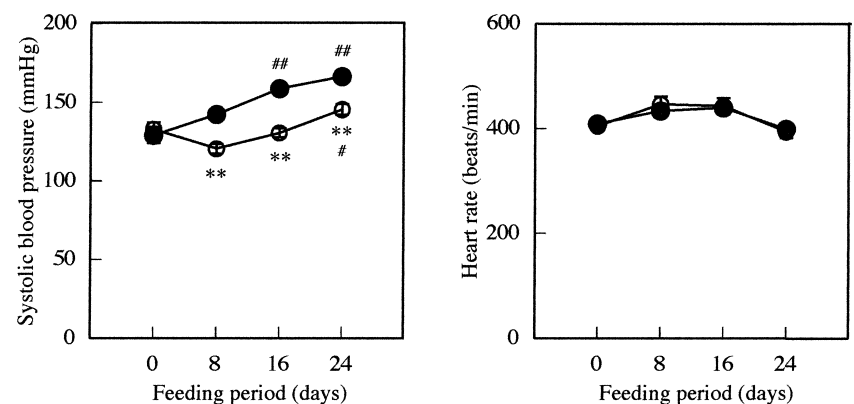

Fig. 1. Effects of 0.5\% Ginkgo biloba Extract (GBE) Diet on Systolic Blood Pressure and Heart Rate in Dahl Rats

The ordinate denotes systolic blood pressure (left) and heart rate (right), while the abscissa indicates the time course $(\mathrm{d})$ after control $(\bullet)$ and $0.5 \%$ GBE $(\bigcirc)$ diets. Each point represents the mean \pm S.E.M. $(n=6)$. $* * p<0.01 v s$. control. \#\# $p<0.05,0.01 v s$. each control $(0 \mathrm{~d})$ terenol-induced positive chronotropic and inotropic effects in atria of GBE rats were not significantly different from those of control rats.

Effect of GBE Diet on Isolated Rat Aorta Figure 3 shows the influence of GBE-containing diet on relaxation induced by acetylcholine and sodium nitropurusside in the aortic rings pre-contracted with noradrenaline $\left(10^{-7} \mathrm{M}\right)$. In the aorta of Dahl rats fed GBE-containing diet for $24 \mathrm{~d}$, the maximum relaxation by acetylcholine $(87.0 \pm 2.4 \%)$ was significantly larger than that observed in Dahl rats fed the control diet $(74.3 \pm 5.3 \%)$. Sodium nitropurusside-induced relaxation was not changed after 24 days' administration of GBE-diet. The contractile force with noradrenaline $\left(10^{-7} \mathrm{M}\right)$ was not significantly different after $24 \mathrm{~d}$ of GBE-containing diet $(0.63 \pm 0.03 \mathrm{~g})$ compared with control diet $(0.69 \pm 0.03 \mathrm{~g})$.
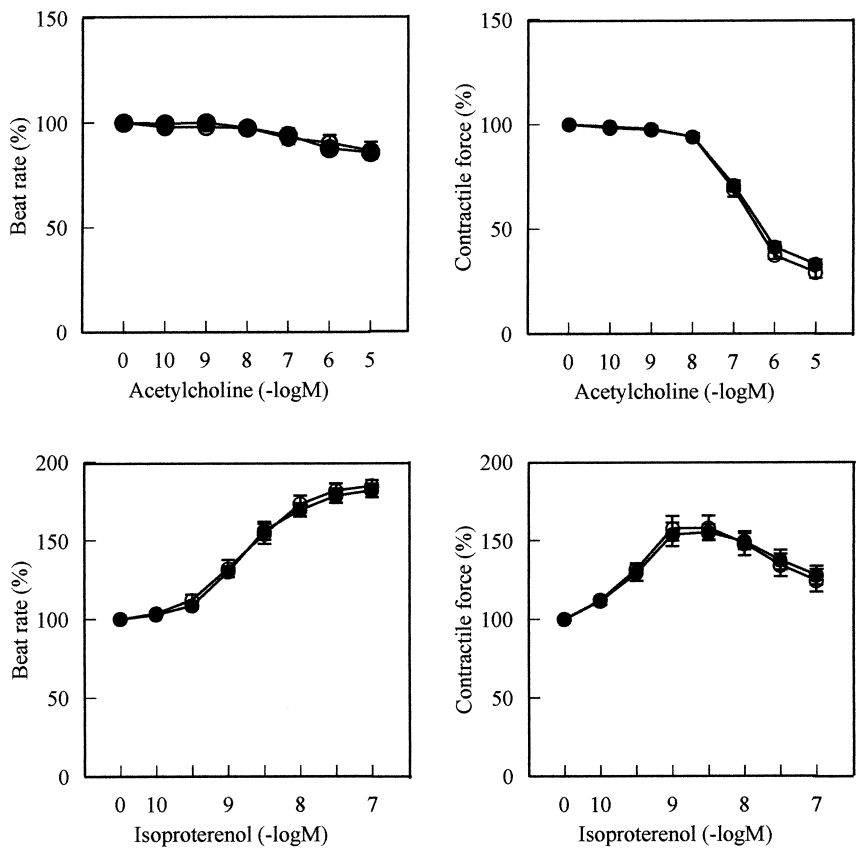

Fig. 2. The Effects of $0.5 \%$ Ginkgo biloba Extract (GBE) Diet on Chronotropic and Inotropic Actions Induced by Acethylcholine and Isoproterenol in the Atria Isolated from Dahl Rats

The ordinate denotes the ratio of beat rate (left) and contractile force (right), and the abscissa indicates the concentration of acethylcholine (upper) and isoproterenol (lower) after control $(\bullet)$ and GBE $(\bigcirc)$ diets. Each point represents the mean \pm S.E.M. $(n=6)$.
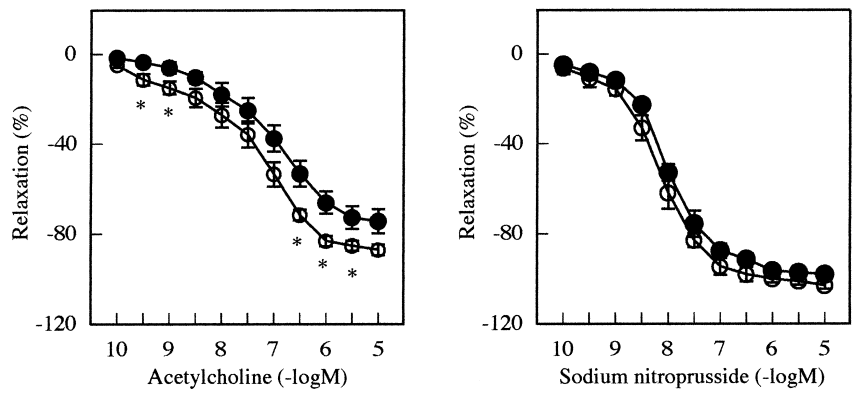

Fig. 3. The Effect of $0.5 \%$ Ginkgo biloba Extract (GBE) Diet on Relaxation Induced by Acethylcholine and Sodium Nitropurusside in the Aortic Rings Preconstricted with Noradrenaline $\left(10^{-7} \mathrm{M}\right)$ Isolated from Dahl Rats

The ordinate denotes the ratio of relaxation (\%) to maximum relaxation in response to papaverine at $10^{-4} \mathrm{M}$ and the abscissa indicates the concentration of acethylcholine (left) and sodium nitropurusside (right) after control $(\bullet)$ and GBE $(\bigcirc)$ diets. Each point represents the mean \pm S.E.M. $(n=6)$. $* p<0.05 v s$. control. 


\section{DISCUSSION}

GBE contains approximately 30 kinds of flavonoids and their derivatives, plus terpenoids such as ginkgolide A, ginkgolide $\mathrm{B}$, ginkgolide $\mathrm{C}$ and bilobalide. ${ }^{10)}$ Our previous study $^{11)}$ demonstrated that GBE produced dose-dependent vasodilation via nitric oxide (NO) synthesis and release by increasing the intracellular calcium level in vascular endothelial cells of rats. We have also suggested that one of the principal ingredients of GBE for bringing about vasodilation is quercetin, which has already been reported to exert antihypertensive effects in spontaneously hypertensive rats (SHR) when administered orally on a long-term basis. ${ }^{1,2)}$ Sasaki et $a l{ }^{12)}$ have shown that the age-related increase in blood pressure observed in SHR was suppressed significantly by GBE at $60-120 \mathrm{mg} / \mathrm{kg}$ each day for 3 weeks. Umegaki et $a l .{ }^{13)}$ have already found that GBE produced antihypertensive effects in deoxycorticosterone acetate-salt hypertensive rats. In the present study, 24 days' administration of GBE caused a significant hypotensive effect in Dahl rats. It is well known that vascular resistance is regulated by the endothelium via the synthesis and secretion of a variety of vasoactive substances, such as nitric oxide, prostacycline, endotheliumderived hyperpolarizing factors (EDHF) and endothelium-derived contracting factor (EDCF). The stable balance of these factors released from the endothelium is disturbed in diseases such as hypertension, atherosclerosis, and diabetes. In hypertension, the endothelium-dependent relaxation induced by a variety of vasodilator agents, such as acetylcholine, is markedly impaired, and this has been documented repeatedly by various investigators. ${ }^{14-18)}$ The overproduction of vasoconstrictor prostanoids ${ }^{14,19)}$ and super oxide anions generated in this pathologic process have been proposed as factors that contribute to the impaired relaxation of vessels to endothelium-dependent vasodilators. $^{15,20)}$ Akpaffiong and Taylor ${ }^{21)}$ have also suggested that either excess production of oxidants or deficiency of antioxidant systems may contribute to high blood pressure and vascular endothelial impairment in SHR. Recently, Sasaki et al. ${ }^{12)}$ reported that the anti-oxidant effects of GBE were increased by measurement of urinary 8-hydroxy-2'-deoxyguanosine.

In our in vitro experiments, relaxation of aortae isolated from Dahl rats in response to acetylcholine was potentiated by long term administration of a GBE-containing diet. Relaxation in response to NO, e.g. sodium nitropurusside-induced relaxation was not affected by treatment with GBE in Dahl. In the aorta of Dahl rats fed on a high-sodium diet, endothelium-dependent relaxations in response to various vasodilators are impaired, while the relaxations in response to the endothelium-independent agonist, sodium nitropurusside, are only slightly impaired. ${ }^{22,23)}$ These findings suggest that enhanced relaxation resulting from GBE administration is due to increased or restored NO production/release from the endothelium or to greater NO bioavailability.

Flavonoids are considered important dietary antioxidants. $^{24)}$ GBE also has antioxidant properties ${ }^{1-3,25)}$ and one of its major active ingredients is considered to be quercetin. Indeed, quercetin was reported to inhibit hypoxanthine-xanthine oxidase activity and scavenge super oxide, hydroxyl radicals, and peroxynitrite in vitro. ${ }^{26)}$ Moreover, metabolites of quercetin after oral administration have also been found to retain the antioxidant properties of the parent compound. ${ }^{27)}$ Superoxide is generally recognized to impair endotheliumdependent vasodilation via inactivation of synthesis and/or release of $\mathrm{NO}$ and consequently to elevate blood pressure. ${ }^{28)}$ Taken together, these findings suggest that the antioxidant properties of the flavonoids within GBE, such as quercetin, may participate in the effects of GBE on blood pressure and endothelium-dependent relaxation observed in the present study. However, further study will be necessary to elucidate the site of action and mechanism of GBE.

In conclusion, the present data demonstrate that GBE reduces the elevation of blood pressure and improves the dysfunction of the NO pathway in the endothelium of Dahl rats. These pharmacological activities are considered to contribute to the possible beneficial properties of GBE in clinical practice, including the regulation of hypertension.

Acknowledgements This study was supported in part by a grant from the Ministry of Health, Labor and Welfare of Japan.

\section{REFERENCES}

1) Haramaki N., Aggarwal S., Kawabata T., Droy-Lefaix M. T., Packer L., Free Radic. Biol. Med., 16, $789-794$ (1994).

2) Koc R. K., Akdemir H., Kurtsoy A., Pasaoglu H., Kavuncu I., Pasaoglu A., Karakucuk I., Res. Exp. Med. (Berl), 195, 117-123 (1995).

3) Pietri S., Maurelli E., Drieu K., Culcasi M., J. Mol. Cell. Cardiol., 29, 733 -742 (1997).

4) Iliff L. D., Auer L. M., J. Neurosurg. Sci., 27, 227-231 (1983).

5) Spinnewyn B., Blavet N., Clostre F., Bazan N., Braquet P., Prostaglandins, 34, 337-349 (1987).

6) Duarte J., Perez-Palencia R., Vargas F., Ocete M. A., Perez-Vizcaino F., Zarzuelo A., Tamargo J., Br. J. Pharmacol., 133, 117-124 (2001).

7) Ibarra M., Moreno L., Vera R., Cogolludo A., Duarte J., Tamargo J., Perez-Vizcaino F., Planta Med., 69, 995-1000 (2003).

8) Dahl L. K., Knudsen K. D., Heine M. A., Leitl G. J., Circ. Res., 22, $11-18$ (1968)

9) Nicholls M. G., Hypertension, 6, 795-801 (1984).

10) "Roken (Ginkgo biloba). Recent Results in Pharmacology and Clinic," ed. by Funfgeld E. W., Spriger-Verlag, New York, 1988, p. 32.

11) Kubota Y., Tanaka N., Umegaki K., Takenaka H., Mizuno H., Nakamura K., Shinozuka K., Kunitomo M., Life Sci., 69, 2327-2336 (2001).

12) Sasaki Y., Noguchi T., Yamamoto E., Giddings J. C., Ikeda K., Yamori Y., Yamamoto J., Clin. Exp. Pharmacol. Physiol., 29, 963-967 (2002).

13) Umegaki K., Shinozuka K., Watarai K., Takenaka H., Yoshimura M., Daohua P., Esashi T., Clin. Exp. Pharmacol. Physiol., 27, 277-282 (2000).

14) Vanhoutte P. M., Boulanger C. M., Hypertens. Res., 18, 87-98 (1995).

15) Jameson M., Dai F. X., Luscher T., Skopec J., Diederich A., Diederich D., Hypertension, 21, 280-288 (1993).

16) Lockette W., Otsuka Y., Carretero O., Hypertension, 8, II61-II66 (1986).

17) Linder L., Kiowski W., Buhler F. R., Luscher T. F., Circulation, 81, 1762-1767 (1990).

18) Taddei S., Virdis A., Mattei P., Salvetti A., Hypertension, 21, 929 933 (1993).

19) Diederich D., Yang Z. H., Buhler F. R., Luscher T. F., Am. J. Physiol., 258, H445-H451 (1990).

20) Fu-Xiang D., Jameson M., Skopec J., Diederich A., Diederich D., J. Cardiovasc. Pharmacol., 20, S190-S192 (1992).

21) Akpaffiong M. J., Taylor A. A., Am. J. Hypertension, 11, 1450-1460 (1998).

22) Luscher T. F., Vanhoutte P. M., Hypertension, 8, 344-348 (1986).

23) Boegehold M. A., Hypertension, 19, 290-295 (1992). 
24) Robak J., Gryglewski R. J., Biochem. Pharmacol., 37, 837-841 (1988).

25) Miyajima T., Yoshikawa T., Kondo M., Food and Free Radicals, [Proceedings of the symposium on Food and Free Radicals], 1st, Yamagata, Japan, June 16, 1994, Meeting Date 1994, 129-130 (1997).
26) Rice-Evans C. A., Packer L. (ed.), "Flavonoids in Health and Disease," Dekker, New York, 1998, p. 541.

27) Manach C., Morand C., Crespy V., Demigne C., Texier O., Regerat F., Remesy C., FEBS Lett., 426, 331-336 (1998).

28) Taniyama Y., Griendling K. K., Hypertension, 42, 1075-1081 (2003). 